\title{
CORPUS Corpus
}

Archivos virtuales de la alteridad americana

Vol 4, No $1 \mid 2014$

Enero / Junio 2014

\section{La naturaleza impura de las cosas folklóricas. Interdisciplina, teleología y elaboración de un archivo huarpe}

Diego Escolar

\section{OpenEdition}

Journals

Edición electrónica

URL: http://journals.openedition.org/corpusarchivos/638

DOI: 10.4000/corpusarchivos.638

ISSN: 1853-8037

Editor

Diego Escolar

Referencia electrónica

Diego Escolar, « La naturaleza impura de las cosas folklóricas. Interdisciplina, teleología y elaboración de un archivo huarpe », Corpus [En línea], Vol 4, No 1 | 2014, Publicado el 25 junio 2014, consultado el

01 mayo 2019. URL : http://journals.openedition.org/corpusarchivos/638 ; DOI : 10.4000/

corpusarchivos. 638

Este documento fue generado automáticamente el 1 mayo 2019.

Licencia Creative Commons: Atribución-NoComercial 2.5 Argentina (CC BY-NC 2.5 AR) 


\title{
La naturaleza impura de las cosas folklóricas. Interdisciplina, teleología y elaboración de un archivo huarpe
}

\author{
Diego Escolar
}

“-¡Pero yo no quiero limitarme a encasillar hechos del Lore; quiero penetrarlo hasta su escondida médula".

Juan Draghi Lucero, La cabra de plata.

1 El presente debate nos invita a reflexionar sobre la relación entre antropología, historia y folklore y para ello se sugiere, además de plantear nuestras opiniones, retroceder sobre las propias experiencias. Por eso, siguiendo de manera no sistemática algunas de las pautas planteadas por Judith Farberman, trataré de abordar la cuestión volviendo los pasos sobre algunos aspectos oscuros de la relación de mi propio trabajo con ese trinomio.

2 En mi libro Los dones étnicos de la Nación, Identidades huarpe y modos de producción de soberanía en Argentina (2007) escribí sobre el resurgimiento de identidades huarpes en la región de Cuyo desde fines del siglo XX y la historia de aquellas poblaciones, hoy consideradas ancestros huarpes, entre principios del siglo XIX y primeras décadas del XX. La investigación que lo sustentó combinó el trabajo de campo etnográfico, la historiografía y de algún modo el análisis literario o genéricamente "del discurso" oral, literario y académico. En el transcurso de la misma, un conjunto de materiales catalogados tradicionalmente como "folklore" se evidenció como un factor central para comprender el proceso de formación y transformación de identidades colectivas en la región. Narraciones sobre hechos del pasado o eventos sobrenaturales que circulan entre poblaciones rurales y urbanas; canciones, rituales, relatos mitológicos sobre héroes rurales; novelas o cuentos de autores locales casi desconocidos, medianamente consagrados, o incluso de peso decisivo en la formación de la literatura nacional. Además, 
mis propios registros de campo o documentos históricos tradicionales y textos académicos sobre etnografía, historia y folklore regional.

El uso que en ese trabajo se hace de estos diversos soportes puede plantear un escenario no muy ortodoxo para un análisis basado en provincias disciplinares rígidas. Pero la posibilidad misma de esa investigación estribó en el modo en que esas piezas fueron deliberadamente liberadas de las clasificaciones de género y atendidas en su ubicuidad y dinamismo, en sus redes intertextuales, los vínculos entre prácticas de las cuales eran parte y la transmutación que enhebraban entre diversos soportes, en las conexiones que se pueden establecer tanto por un lado con otros textos y prácticas sociales, como con eventos históricos y memorias colectivas. Esta perspectiva se contrapone a dos de las principales concepciones a las que se asocia el folklore y que persisten en forma visible o encubierta. La de tradición, como reproducción estetizada de núcleos originales de cultura, eventualmente capaces de sostener cierto tipo de identidades primordiales de generación en generación. La de tipología, según la cual el principal fin del folklore como disciplina se asocia a la clasificación de textos y formas. Pero no obstante ello, el folklore, en cualquiera de estas acepciones (como tradiciones y leyendas, como "tesoro" de arte popular o como determinados géneros o estilos discursivos y performances), formaba parte del resurgimiento de identificaciones huarpes en Cuyo y su productividad a través del tiempo.

\section{Redes textuales, folklore e historia}

Desde que comencé mis trabajos etnográficos en la región cuyana en 1994, noté que existía un déficit de publicaciones históricas sobre las poblaciones campesinas o sectores populares en general. Esto contrastaba con la relativa profusión de obras literarias que retrataban a esas mismas poblaciones que evocaban detalles sobre la vida cultural, las relaciones sociales, los conflictos políticos y las identidades populares completamente ausentes en la escritura académica. Esta literatura se remonta a las primeras obras de Sarmiento sobre San Juan y Cuyo, pasando por autores como Pedro Echagüe, Juan Draghi Lucero y Antonio Di Benedetto, recalando luego en semblanzas periodísticas, folletos y poemas. Estos textos, no solo describiendo imaginativamente sino recogiendo narrativas orales y expresiones populares en forma explícita o encubierta, proporcionaban relatos históricos o memorias que sugerían datos invaluables sobre la perspectiva de los sectores populares rurales que eran los grandes ausentes en la historiografía ${ }^{1}$. Por ejemplo, mientras la extinción de población e identidades indígenas en Cuyo desde mediados del período colonial hispano aparecía en las obras de historia y antropología autorizadas como un hecho incuestionable, en esta literatura más ecléctica abundaban todo tipo de referencias a identidades, prácticas culturales, eventos históricos, mitos y fantasmas huarpes o indígenas.

Claro está que no se trataba de tomar mecánicamente estas imágenes o relatos como crónicas etnográficas. Pero la producción estrictamente historiográfica tampoco se revelaba como una aproximación más autorizada a la historia campesina e indígena. A la escasez de análisis sobre la historia social rural, buena parte de los enunciados históricos sobre estos grupos se basaban en lugares comunes teñidos de socio y etnocentrismos. Más aún, desde un concepto conservador de folklore como tradiciones reproducidas de una manera acrítica y emotiva y cuyos contenidos se dan por hechos incuestionables, no obstante la falta de contrastación empírica, la producción historiográfica se revelaba, en 
gran medida, como folklórica. Tomemos por ejemplo lo que denominé la "narrativa de extinción" huarpe. Hasta ahora, la historiografía y etnohistoria regionales dan por sentado que la población indígena del centro y norte de Cuyo se extinguió en el siglo XVII por las levas masivas a Chile, o por el reemplazo de su cultura por una de origen europeo. Esta aseveración, sin embargo, no es casi en ningún caso producto del análisis, sino un axioma que tiene más que ver con la autoimagen de clase y étnica de los autores que con un análisis profundo de la información disponible. Y en este sentido reproducen un conjunto de discursos elaborados desde el siglo XIX (aunque con raíces en el XVII) que por distintas causas han presionado para alienar la indigenidad de la identidad colectiva de las provincias cuyanas o sus poblaciones, al menos durante la mayor parte de la historia local.

Al indagar la dinámica histórica de las identidades indígenas en Cuyo no había razón entonces para limitar mi análisis a bibliografía histórica o a fuentes históricas tradicionales. En realidad, mi opción derivaba también de una postura teóricometodológica que está en la base del eclecticismo con que traté las fuentes. Si bien hasta aquí distinguí operativamente entre "historiografía" o "discurso académico", y "literatura" o "narrativas populares" y aun (con reticencias) "folklore", en rigor considero que no es fácil ni demasiado útil establecer una clara distinción entre estos distintos géneros. Los textos historiográficos, independientemente de su valor científico, pueden ser también "fuentes" en sí mismas, como a su modo cuentos, reportes etnográficos, novelas, artículos periodísticos o la narrativa oral recabada en el trabajo de campo. Y materiales ligados a la literatura o el folklore pueden tener un valor historiográfico; como así también textos académicos constituir piezas etnográficas. Finalmente, puede decirse -y este es el caso tratado- que existen también "folklores científicos" según los cuales, por ejemplo, historiadores, antropólogos, geógrafos y arqueólogos reproducimos contenidos y formas discursivas articuladas con atributos estéticos, emotivos y supuestos de verdad (como la narrativa de extinción indígena) que escapan al análisis teórico o la contrastación empírica. En este sentido, finalmente no había un folklore sino muchos y con significados antagónicos aunque, como veremos más adelante, con contenidos sorprendentemente semejantes.

7 Mi aproximación a ese universo dispar fue al principio errática. De acuerdo a mis objetivos iniciales, terminé reuniendo un corpus heterogéneo de textos, integrándolos por sus referencias directas o ubicuas a nociones de indigenidad o aboriginalidad.

8 Si tomaba en cuenta que las identidades colectivas son producto en muy gran medida de la circulación de discursos que elaboran y reproducen imágenes o argumentos de distinción grupal, la historización de estos discursos era una tarea ineludible, tanto para comprender los procesos identitarios en la actualidad como su historia misma. Y si bien esos discursos que articulan identidades son producto también de relaciones y acciones sociales y políticas, los recursos para su estudio son fundamentalmente soportes discursivos. Sin abundar en una larga disquisición lingüística, tenemos entonces que un trabajo serio sobre las identidades debe ser necesariamente histórico y debe contemplar tanto la historia de discursos como la historia de relación de los mismos con una historia "dura" de relaciones sociales, políticas y económicas, y, obviamente, reconstruir esta historia o sus aspectos más influyentes en la conformación de las representaciones identitarias. El resurgimiento de identidades huarpes, en suma, está atravesado, posibilitado y en gran medida generado por regímenes discursivos cuya formación y 
productividad es parte también de la historia "dura" de relaciones sociales, políticas y económicas.

Esta perspectiva múltiple es una de las primeras dificultades que enfrentan la mayoría de los estudios sobre identidades, dado que obviamente requiere, además de un trabajo a veces más extenso que el interés del público por los fenómenos estudiados, el tiempo necesario para el desarrollo de un amplio abanico de habilidades, metodologías y conocimientos que suelen exceder las formaciones disciplinarias y la paciencia de nuestros contratantes y evaluadores en la comunidad científica.

\section{El archivo huarpe}

10 Partiendo de la noción de "archivo huarpe", propongo reinscribir el folklore cuyano en un proceso de etnogénesis indígena a lo largo de los siglos XIX y XX. Expandiendo el significado de este concepto, no entiendo por tal a la consolidación de un grupo étnico a través de la articulación histórica de una cultura común que pasa a constituir el referente de su identidad; ni tampoco solamente a la producción histórica de signos y mitos de identificación colectiva, que crean nuevas identidades a partir de conflictos (aunque eso es un aspecto importante). Sino también, sobre todo, a la articulación de memorias étnicas y políticas de larga duración, generadas y sostenidas tanto por miembros del grupo como de alguna manera por el resto del entramado social al que pertenecen, incluso si esta pertenencia se produce mediante relaciones de oposición, exclusión o guerra, e independientemente de la existencia del reconocimiento explícito de una identidad común ${ }^{2}$. En esta breve contribución me interesa mostrar, a partir del caso "huarpe", cómo operó en este proceso la producción "folklórica" o la folklorización de la memoria colectiva como nodo de representación y transacción de experiencias históricas y sistemas de clasificación social, y al mismo tiempo como un corpus que "encriptó" significados de la historia regional.

11 Cuando hablo de un archivo huarpe obviamente no me refiero a la existencia de un espacio físico o institucional que preserve documentos, o a una serie de colecciones documentales atesoradas y sujetas a regímenes burocráticos de acceso. Tampoco la noción postestructuralista donde el concepto de "archivo" puede expandirse hasta incorporar como tal prácticamente toda pauta clasificatoria. Mi concepción es, si se quiere, intermedia. En un sentido amplio, me refiero al conjunto de textos o soportes discursivos (escritos, orales, rituales, performáticos) que pueden ser articulados entre sí por las referencias que de ellos es posible sustraer sobre un tema o para iluminar un campo temático específico de conocimiento. Textos o discursos que no poseen una integración física, institucional o clasificación reconocida. El archivo en este sentido no se define por la localización, institucionalización o clasificación previa de los materiales, o los materiales por sí mismos, sino por la perspectiva de un observador que enhebra tales relaciones en base a algunos principios. Si estas están no formuladas, no quiere decir que el archivo no exista potencialmente, sino que aún no ha sido articulado como tal. Lo que es central en la operación archivística es, entonces, el principio articulador que hace del archivo un artefacto virtual que reclasifica, más que un conjunto discreto de fuentes.

Esto implica que en última instancia todo archivo tiene un componente teleológico que es necesario reconocer para que no se transforme en un principio hermenéutico implícito que oriente su análisis. Para ejemplificar este último punto podemos tomar el caso de los archivos (ahora si en el sentido institucional) nacionales o provinciales. Estos repositorios 
pueden contener un muy diverso conjunto de documentos, inclusive de períodos anteriores a la formación de la organización estatal de la cual dependen, o de la nación o provincias mismas que dan nombre y legitimidad al archivo y status de "documentos" a los textos que guardan. Sin embargo, lo que brinda coherencia al archivo no es tanto que los documentos hayan sido producidos por instituciones o agentes del Estado sino el supuesto de que los sucesos históricos a los cuales los textos que en él están depositados se relacionan con el desarrollo de los procesos que desembocaron en la existencia de dicho Estado, nación o provincia. El archivo "oficial" requiere entonces siempre de una acción constituyente que supone una previa interpretación de la existencia de un sujeto histórico de referencia, proyectado hacia el pasado y hacia el futuro.

Es obvio que la condición de verdad, objetividad u originalidad de estas representaciones o de los propios materiales es irrelevante para definir la verdad del archivo como tal. El Archivo General de la Nación es verdadero en el sentido de que ha sido constituido y reconocido socialmente como tal en función de una perspectiva más o menos compartida sobre la existencia de la nación, y es reproducido institucionalmente. Sin embargo, los materiales que están acopiados no necesariamente, o no solamente, sustentarán la idea de la existencia de esa nación y su pasado, o los términos en los cuales sus fundadores la pensaban, y pueden ser analizados de diferentes maneras, algunas de las cuales permitirán ulteriormente socavar sus propios fundamentos. Finalmente, estos archivos son criaturas caníbales, vórtices en los que los archivos de los "otros" de esa misma nación puede ser incorporados con las condiciones apropiadas de apropiación. Este es el caso por ejemplo, de los documentos indígenas como las cartas escritas por el cacique Sayhueque o sus secretarios, recibidas por militares, políticos, comerciantes, científicos y otros caciques durante las campañas de ocupación argentina del área pampeana y patagónica (Vezub, 2009). En parte, el Archivo General de la Nación y otros archivos nacionales y provinciales incorporaron esos documentos subrepticiamente a través de diversas colecciones y donaciones. Pero no obstante su localización dispersa, y realizando un trabajo arqueológico en las estratigrafías textuales de varios corpus y repositorios, Vezub reconstruyó un archivo virtual de la Gobernación indígena de Las Manzanas, integrándolos y reclasificándolos como "secretaría" indígena.

aproximación fue diferente ya que no se limitó a reunir materiales dispersos que constan en archivos institucionales, sino que integró un conjunto mucho más diverso, conformando un archivo virtual de fuentes no clasificadas por género ni soporte. Primero, documentos explícitamente producidos por o sobre los huarpes, e incorporados en algún archivo (en el sentido lato del término). Segundo, toda clase de soportes discursivos (escritos y orales) donde lo huarpe y los huarpes han sido referidos tangencialmente, o aun de forma implícita, deducible solo por la relación que podemos establecer con otras piezas textuales y las redes de referencias que hemos establecido previamente. Estas integraciones previas, como un efecto dominó, van permitiendo releer y ampliar el campo de referencias en textos que ni siquiera los nombran pero sí versan sobre temas y argumentos que en otros textos ya integrados han sido asociados a los huarpes.

Por ejemplo: Santos Guayama, conocido caudillo cuyano de las décadas de 1860 y 1870, es calificado como cacique huarpe en algunas memorias orales de Cuyo, y ocasionalmente como descendiente de huarpes en la literatura regional y algunos trabajos históricos. No obstante, no conozco hasta el momento una sola fuente de época que lo determine como huarpe, aunque eventualmente sí como indio. Las memorias orales, las obras literarias 
donde Guayama es representado como descendiente de huarpes y los trabajos históricos que toman este folklore, son susceptibles en principio de integrarse en un archivo huarpe. A su vez estas referencias permiten, siguiendo la misma metodología archivística, releer otras fuentes orales y escritas sobre Guayama desde una perspectiva "huarpológica", en la medida en que se encadenan con uno o más tópicos que ya han sido articulados en la serie. Fuentes de cualquier índole que refieren a actores o grupos asociados a las imágenes huarpes en esos discursos, como por ejemplo los laguneros de Guanacache, o los arrieros sanjuaninos, o los montoneros cuyanos, los cosechadores o puesteros actuales.

$\mathrm{El}$ archivo huarpe fue entonces construido como el conjunto de materiales discursivos susceptibles de ser articulados por la existencia en ellos de (o la inferencia de que en ellos existen) referencias explícitas o implícitas no solo a los huarpes como sujetos sino a la "huarpidad". Esto es, imágenes, nociones, representaciones sobre la condición huarpe de ciertos sujetos, eventos u objetos materiales y simbólicos. En segunda instancia, la rearticulación desde una perspectiva "huarpe" (tal como los significados de lo huarpe van adquiriendo cierta lógica o conexión entre sí) de otros discursos, textos o fuentes, que no mencionan explícitamente a los huarpes. Forzando el uso de un concepto forjado en la etnografía amazónica para cuestionar la noción universal de humanidad y su distinción de la naturaleza, podemos calificar nuestra visión del archivo huarpe con relación a la nación como una suerte de "perspectivismo"3 según el cual la historia generada o reconstruida podrá ser argentina o indígena, o huarpe por caso, porque sus materiales no son sustento intrínseco de identidades o colectividades fuera de la hermenéutica o el punto de vista que los organiza. En el canibalismo archivístico, el archivo huarpe crece parasitariamente dentro del universo archivístico nacional o provincial, a través de una lógica similar a la de estos pero inversa, de modo que cada vez más materiales y temas pueden ser integrados en sus redes de interpretación y relación. Por ejemplo, un mapa catastral de las Lagunas de Guanacache de comienzos del siglo XX, el Facundo, Una excursión a los indios ranqueles, un discurso de Mitre sobre el estado de sitio, fotos de los laguneros de la década de 1920, los relatos sobre salamancas de narradores locales, son fuentes "huarpes" cruciales en la medida en que las contextualizamos desde una teleología huarpe, donde una institucionalidad o el desarrollo de una historia pensada como nacional no es el marco subyacente. Como hemos discutido en un reciente seminario ${ }^{4}$, estos archivos forman parte también de redes socio-materiales entre objetos y personas. Se cruzan y hacen nodos con una red de relaciones con personas y cosas, como las "piedras pintadas" de Barreal, la estatuilla de San Roque (que personifica a Guayama) en la capilla de Rosario de las Lagunas, la cruz de cemento erigida para espantar a las brujas en la villa de emergencia al pie del cerro Villicún, en la ciudad de San Juan, los restos de basura mecánica y puntas de flecha en los médanos de Guanacache o los papeles copiados con reclamos y procesos judiciales sobre tierras indígenas durante el siglo XIX, guardados como fetiches en archivos familiares locales. También con prácticas, como la caza furtiva de guanacos, el rastreo de huellas, la construcción de una ramada, la charla de fogón, la realización de una asamblea, un petitorio para la instalación de una escuela o una fiesta patronal. Y por supuesto, en esta perspectiva, es muy difícil separar tajantemente el trabajo propiamente historiográfico del trabajo de campo etnográfico y viceversa. Resulta casi inevitable interpretar "fuentes" y "experiencias de campo" inspirándose mutuamente unas y otras, documentos por ejemplo sobre historia política de la campaña cuyana y repertorios políticos actuales, o representaciones actuales de cultura y racialidad huarpe y aquellas de recopilaciones folklóricas de 1920 o de libros de Sarmiento. 


\section{Folklore e identidad} que un objeto es folklórico porque contribuye a definir identidad grupal en contraposición a un "otro" también colectivo ${ }^{5}$.Volviendo al tema de las identidades huarpes, esta definición (por cierto limitada y demasiado amplia a la vez) es problemática cuando observamos que no es sencillo encontrar una narración o texto que claramente marque o precise identidad huarpe en tanto atributo de un sujeto concreto, o que inequívocamente afirme o deniegue la existencia de los huarpes. Tomando por caso la producción literaria inspirada en tradiciones orales y el folkore histórico presente en textos académicos, la mayoría de esos textos son contradictorios en cuanto a la existencia real de los huarpes. En Recuerdos de Provincia Sarmiento afirma que los huarpes están extinguidos, no obstante dedique un capítulo a ellos (la primera referencia conocida sobre los huarpes desde el siglo XVII) insinuando la existencia de prácticas culturales y población huarpe contemporánea. Draghi Lucero por ejemplo sostiene asimismo que los huarpes se extinguieron, pero permanentemente alude a resabios huarpes de la población campesina de $\mathrm{Cuyo}^{6}$, e historiadores locales insisten por demostrar la extinción indígena temprana aunque los propios documentos que analizan evidencian la existencia de demandas indígenas y población identificada como indígena uno o dos siglos después de la supuesta desaparición ${ }^{7}$. Uno de los mejores ejemplos de esta dinámica contradictoria es el escritor local Juan Pablo Echagüe. En el raconto histórico-literario de San Juan, Tierra de huarpes (1945a), escrito según dice el autor sobre las ruinas del terremoto de San Juan de 1944 para pedir ayuda al gobierno nacional en la reconstrucción de la ciudad, sostiene que

De todo este mundo indígena (...) nada queda en el presente. La raza crepuscular se extingue: sus culturas se han derrumbado. Sólo el poeta o el investigador buscan su rastro (...) El destino ulterior de la provincia ha escapado a la influencia de los indios, $\mathrm{y}$, sin embargo, algo quedó de todos ellos en la región; algo que atravesó los tiempos como una fuerza viva (Echagüe 1945a, p. 42).

En Hechizo en la montaña (Echagüe, 1945b) los baqueanos son intérpretes, transmisores o incluso actores de los indicios huarpes. Durante un viaje iniciático a Chile del joven hijo de un terrateniente con un arreo de mulas, el baqueano no cesa de inculcar en el niño las memorias y resabios huarpes. Indica una vieja bocamina donde brotan ánimas porque habrían muerto "a montones los indios que trajeron a trabajar en las minas en tiempo de los españoles" (Echagüe, 1945b, p. 42). En el fogón nocturno, comienza sus relatos con el Húnuc-Huar ("el dios de los huarpes") y narra un mito de creación de la cordillera de lo Andes (Echagüe, 1945b, p. 43). Luego, hace permanentes alusiones a las prácticas culturales contemporáneas connotando su origen indígena "Quien haya de cazar guanacos (...) ha de tener el pie firme como de indio guarpe (Echagüe, 1945b, p. 50)".

En realidad, si algo sugirió la investigación aquí presentada es que las identificaciones huarpes, si bien apoyadas (como todas las identidades) en discursos, son bastante independientes del carácter afirmativo o impugnador de los mismos sobre la existencia de los huarpes como colectivo social concreto. Es decir, tanto aquellos que en distintas épocas proyectaron identidades huarpes sobre poblaciones concretas, como quienes eventualmente se autoadscriben o adscribieron, reciclan un universo folklórico sobre caracteres, raza, cultura o historia huarpe producido y reproducido por distintos agentes aunque estos hayan negado la existencia de los huarpes. Así, descripciones y análisis de la 
cultura y lengua huarpes del período colonial temprano realizados por etnohistoriadores que, como Salvador Canals Frau, denegaban toda posibilidad de existencia de este pueblo más allá del siglo XVI, o tonadas recopiladas por Draghi Lucero en su Cancionero cuyano (1938), son invocados como inspiración estética y fuente para los adscriptos huarpes del presente. Pero a su vez, estos textos o canciones tienen al menos parte de su origen en narraciones orales de esos mismos grupos o incluso en experiencias de campo de sus autores, como se infiere por ejemplo en Donde haya Dios de Alberto Rodríguez (1958), Martina Chapanay, realidad y mito de Marcos Estrada (1962) o las ya mencionadas Hechizo en la montaña (Echagüe,1945b) o La cabra de plata (Draghi Lucero, 1978).

20 Esto debe llamar la atención sobre miradas ingenuas o "literales" respecto de las adscripciones étnicas y señala también nuevamente el límite de un enfoque exclusivamente discursivo sobre la formación de identidades.

21 Si hay algo difícil al analizar las cadenas intertextuales por las cuales se transmiten y reproducen algunos de los tópicos centrales de la huarpidad es precisamente encontrar un origen o una "voz" asociada a un sujeto social. La Martina Chapanay, bandolera y montonera de las travesías cuyanas durante el siglo XIX y, al igual que Santos Guayama, considerada por muchos cacique huarpe, es uno de los personajes principales del panteón de héroes de la épica huarpe. He recabado numerosos relatos sobre la Martina y conocido a varias personas que dicen ser sus descendientes, funcionando, al igual que Guayama, como "próceres" de la proto-nación huarpe en formación y como tales, padres refundadores figurados del pueblo huarpe. Las descripciones sobre la Martina y sus acciones son un compendio de los conflictos, vida cotidiana, lengua, historia y economía política de las poblaciones rurales de Cuyo de los siglos XIX y XX. También hay una frondosa literatura sobre la Martina que arranca en 1865 con una inhallable pieza de Pedro D. Quiroga (fundador el mismo año de la biblioteca Franklin de San Juan, la primera biblioteca popular de la Argentina) y, solo por citar los textos más significativos, continúa con La Chapanay de Pedro Echagüe de 1884 (1930), La Martina Chapanay. Poema histórico, de Julio Fernández Peláez (1934), que inspiró la cueca La Martina Chapanay de Los Trovadores de Cuyo en la década de 1940, la novela histórica ya citada de Marcos Estrada y el estudio folklórico La Leyenda de Martina Chapanay, de Susana Chertudi (1971) basada en la Encuesta de Folklore de 1921, donde se recopilaron numerosos relatos sobre Martina Chapanay.

Susana Chertudi y Sarah Newbery efectuaron uno de los estudios más significativos del folklore argentino sobre los relatos de la Difunta Correa y uno menor sobre los de la Martina Chapanay, recogiendo la mayoría de ellos de la Encuesta correspondiente a San Juan. Ambos personajes eran emblemáticos de la narrativa popular cuyana de la época. Las autoras basaron su análisis en las clasificaciones de los tópicos o motivos presentes en las narrativas en tanto manifestaciones particulares de arquetipos universales como los presentados en el Motif-Index of Folk-Literature de Stith Thompson (1955-1958). Para ello realizaron una transcripción de todas las versiones que encontraron en la Encuesta, más algunas recopiladas personalmente por Chertudi. Los resultados son, sin embargo, un poco decepcionantes para el interés tanto de la historia como de la antropología. En el caso del largo artículo sobre la Difunta Correa (Chertudi y Newbery, 1971), se señalan en forma descriptiva la amplia difusión geográfica de su culto y los principales tópicos de su narrativa, relacionados con la creencia en el poder de los espíritus de los muertos en circunstancias trágicas y en los favores o castigos que la Difunta proporciona, que dan pie a un conjunto de rituales propiciatorios e interdicciones (Chertudi y Newbery, 1971, p. 176). Respecto de la leyenda de Martina Chapanay, se concluye que "Se han detallado los 
elementos presentes en las distintas versiones y se mantiene la clasificación ya propuesta, de leyenda histórica, propia del folklore del área cuyana" (Chertudi y Newbery, 1971, p. 236). Esta obsesión clasificatoria ha teñido en gran medida los estudios de folklore hasta períodos muy recientes, cuando la gran mayoría de los análisis giran en torno a definir si y cuándo un texto (o una práctica performativa) puede ser calificado como folklórico, en lugar de tratar de ver qué conocimiento social, o para el caso, histórico, puede proporcionarnos el análisis de dichos materiales o eventos.

En este sentido, un uso más productivo es el que hizo Ariel de la Fuente (2007) de la propia Encuesta o de estudios de folkloristas ${ }^{8}$,utilizando textos de canciones y relatos históricos centrados en Facundo y El Chacho para explorar lo que denominó una cultura popular "gaucha" (como hipóstasis de los grupos populares rurales de las provincias interiores, La Rioja y Cuyo especialmente) y el modo en que esta estuvo atravesada por la identidad política federal y la experiencia de las guerras civiles argentinas. El autor también, al modo de Chertudi y Newbery, omitió considerar el universo discursivo más general de los materiales de la Encuesta y extrajo algunas piezas referidas explícitamente al período estudiado y algunos de sus personajes más relevantes. Notablemente, ni Chertudi y Newbery se extendieron más allá de los relatos sobre la Chapanay o la Difunta Correa, ni De la Fuente consideró aquellas, pese a que los relatos sobre estas mujeres y los de las guerras civiles del siglo XIX están inextricablemente coligados en la Encuesta.

Una visión de conjunto sobre la sección sanjuanina de la Encuesta arroja la prevalencia de una serie de motivos. Por un lado los ya analizados por Chertudi y Newbery, siete relatos basados en la Chapanay y cinco en la Difunta Correa. Pero en igual o mayor proporción contamos con al menos seis relatos que mencionan al caudillo Santos Guayama, once que discurren sobre hechos de las insurrecciones montoneras de las décadas de 1860 y 1870 y su represión (a los que debe sumarse la mayoría de los que refieren a Chapanay, Guayama o la Difunta Correa), y al menos doce que hablan sobre los huarpes, o que versan genéricamente sobre los "indios".

25 Ya se ha señalado de un modo convincente que la Encuesta constituyó un aparato de formación de la identidad nacional, resignificando al criollo como su tropo predilecto, evocando y subsumiendo lo indígena en la formación de un imaginario de comunidad nacional criolla (Blache y Dupey, 2007; Chamosa, 2008). Sin embargo, me limitaré a señalar que del mismo modo que podemos interpretarla como un esfuerzo de nacionalización cultural, también constituye de hecho un vehículo más de transmisión de discursos que contradicen esta tendencia, como tradiciones indígenas, inventadas o no, en una cadena que no se ha cortado hasta el momento y puede ser recuperada y resignificada. Los textos que hemos mencionado, al igual que en la narrativa oral, poseen siempre contradicciones internas y reproducen o pueden reproducir corrientes discursivas o valoraciones contrapuestas en largos períodos. Es erróneo entonces calificar una instancia textual como testimonio definitivo que clausura o inaugura una identidad. Pero también apresurarse a otorgarles una autoría o "voz" única, o una "memoria" en el sentido de expresión colectiva de un grupo. Como las historias, memorias y archivos nacionales y provinciales, las memorias huarpes $-\mathrm{y}$ su archivo- no pertenecen solo a los huarpes concretos o sus descendientes, ni ha sido elaborada y transmitida exclusivamente por estos o sus ascendientes. 


\section{BIBLIOGRAFÍA}

Blache, M. y Magariños de Morentin, J. A. (1988). Lineamientos metodológicos para el estudio de la narrativa folklórica. Revista de Investigaciones Folklóricas, 2, 16-19.

Blache, M. y Dupey A. M. (2007). Itinerarios de los estudios folklóricos en la Argentina. Relaciones de la Sociedad Argentina de Antropología, XXXII, 299-317.

Canals Frau, S. (1946). Etnología de los huarpes. Una síntesis. Anales del Instituto de Etnología Americana, t. VII, 9-147.

Chamosa, O. (2008). Indigenous or Criollo: The myth of white Argentina in Tucuman's Calchaquí Valley. Hispanic American Historical Review, 88(I), 71-106.

Chertudi, S. y Newbery, S. (1967). La difunta Correa. Cuadernos del Instituto Nacional de Antropología, 6 (1966-1967), 95-178, Buenos Aires.

Chertudi, S. (1971). La Leyenda de Martina Chapanay. Cuadernos del Instituto Nacional de Antropología, 7 (1968-1971), 223-237.

De la Fuente, A. (2007). Los hijos de Facundo. Caudillos y montoneras en la provincia de La Rioja durante el proceso de formación del Estado nacional argentino (1853-1870). Buenos Aires: Prometeo.

Draghi Lucero, J. (1938). Cancionero popular cuyano. Mendoza: Best Hermanos.

Draghi Lucero, J. (1978). La cabra de plata. Buenos Aires: Castañeda.

Echagüe, J. P. (1945). Hechizo en la montaña. Buenos Aires: Kraft.

Echagüe, J. P. (1945). Tierra de huarpes. Buenos Aires: Kraft.

Escolar, D. (2007). Los dones étnicos de la Nación. Identidades huarpe y modos de producción de soberanía estatal en Argentina. Buenos Aires: Prometeo.

Escolar, D. (2013). Huarpes Archives in the Argentine Desert: Indigenous Claims and State Construction in Nineteenth-Century Mendoza. Hispanic American Historical Review, 93, 451-486.

Echagüe, P. (1936). Dos novelas regionales. Buenos Aires: W. M. Jackson.

Estrada, M. (1962). Martina Chapanay. Realidad y mito. Buenos Aires: Imprenta Varese.

Fernández Latour, O. (1960). Cantares históricos de la tradición argentina:

Selección, introducción y notas. Buenos Aires: Instituto Nacional de Investigaciones Folklóricas.

Fernández Peláez, J. (1934). La Martina Chapanay. Poema histórico. Mendoza: S.E.

Magariños de Morentin, J. A. (1993). El contexto de interpretación de los fenómenos folklóricos. Revista de Investigaciones Folklóricas, 8, 19-22.

Michieli, C. T. (2004). La fundación de villas de San Juan (siglo XVIII). Buenos Aires: Sociedad Argentina de Antropología.

Rodríguez, A. (1958). Donde haya Dios. Buenos Aires: Lautaro.

Sarmiento, D. F. (1947 [1866]). El Chacho. Último Caudillo de la montonera de los llanos. En Vidas de Fray Félix Aldao y El Chacho (pp. 69-236). Buenos Aires: Argos. 
Sarmiento, D. F. (1963 [1845]). Facundo. Buenos Aires: Ed. Losada.

Sarmiento, D. F. (1966 [1850]). Recuerdos de provincia. Buenos Aires: Ed. Sopena Argentina.

Vezub, J. E. (2009). Valentín Saygüeque y la Gobernación de las Manzanas. Poder y etnicidad en la Patagonia Septentrional (1860-1881). Buenos Aires: Prometeo.

\section{NOTAS}

1. Más adelante pude comprobar que esta escasa presencia historiográfica no necesariamente implicaba una carencia de fuentes históricas, incluso clásicas o de archivo en el sentido tradicional. Análisis sobre fuentes como censos, pleitos judiciales, cartas e informes de viajeros que aportan información sobre historia indígena moderna en el centro de Cuyo pueden consultarse, entre otros trabajos, en Escolar 2007 y 2013.

2. He tratado extensamente este tema en Escolar 2007.

3. Me refiero a Eduardo Viveiros de Castro y su conocida teoría de la mutua y constitutiva predación de los sujetos y objetos sociales (y naturales). Ver un compendio de esta postura en Metafísicas caníbales (2010).

4. Se trató de la reunión realizada en 2011 Las identidades como redes socio-materiales: Perspectivas desde Sudamérica y más allá (University of Exeter, Arts \& Humanities Research Council) coordinado por Marisa Lázzari y Alejandra Korstanje en Horco Molle, Tucumán.

5. Esta postura está representada en varios trabajos de folkloristas antropológicos argentinos, por ejemplo Blache y Magariños (1987), Magariños (1993).

6. En su recopilación Cartas y Documentos coloniales de Mendoza, Draghi Lucero expresa que "A los 120 años de fundada Mendoza [1561] ya casi no se hallaban huarpes" (Draghi Lucero, 1993, p. 20 ). Al final del prólogo de la novela La cabra de plata, sobre los laguneros de Guanacache, afirma que "lo documentado, cierto y valedero fue que este pacífico pueblo fue prontamente exterminado" (Draghi Lucero 1978, p. 8). Pero el libro se estructura sobre el tema de un viejo profesor especialista en historia y folklore, escéptico de la existencia de los huarpes, que deprimido por su retiro y agobiado por la modernidad opresiva de la ciudad y la universidad, va a vivir una temporada en Guanacache para re-descubrir fantasmas, mitos, olores y saberes huarpes. Al final el profesor termina renegando de la ciencia para pasar a "vivir" el folklore y la historia, en lugar de estudiarlos (Draghi Lucero, p. 324).

7. Ver por ejemplo Michieli 2004.

8. Principalmente de Olga Fernández Latour en Cantares históricos de la tradición argentina (1960).

9. Notoriamente, este rico acervo para el estudio de las conflagraciones, sociedad y cultura popular del período, apenas si fue estudiado por historiadores, inclusive aquellos que, como De la Fuente, explícitamente enfocaron la Encuesta como parte sustancial de su corpus. 


\section{AUTOR}

\section{DIEGO ESCOLAR}

IANIGLA (Instituto Argentino de Nivología, Glaciología y Ciencias Ambientales), CONICET (Consejo Nacional de Investigaciones Científicas y Técnicas)-Universidad Nacional de Cuyo, Argentina.

Correo electrónico: descolar@gmail.com 